Larger bronchi congested; bases of lungs œdematous. There was very little macroscopic evidence of fibroid infiltration from the pleura and no visible bronchiectasis. The bronchial glands were inflamed, slightly enlarged; no signs of suppuration or caseation. No macroscopic evidence of tubercle in glands, lungs, or pleura. No evidence of atheroma in pulmonary arteries.

Abdomen: Peritoneum: There was about 10 ounces of pale straw-coloured fluid in the pelvis. The parietal peritoneum and the omentum appeared normal. In mesentery of small intestine and mesocolon were about ten milky-white areas, the largest 2 by 1 inch. The thickness in the centre was about $1 / 12$ inch, gradually thinning out until it blended with normal peritoneum. No appreciable shortening of mesentery and no fibrosis of omentum. The mesenteric glands were normal. Liver: Slightly enlarged and showed congestion, with some fatty change. On diaphragmatic surface of left lobe, extending for a short distance on to the right lobe, the capsule showed slight diffuse thickening, but no infiltration of flbrosis into liver tissue. Spleen: Slightly smaller than normal, the spleen showed to perfection the "cake-icing" condition described by Adami. The whole of the convex surface was covered with a dense, porcelain-like, hyaline tissue, inch thick, terminating somewhat abruptly at margins of spleen, and fusing into apparently normal splenic capsule. No fibroid invasion of splenic tissue. Kidneys, adrenals, pancreas, bladder, stomach, intestines, and blood-vessels appeared normal.

The interesting features were the negative history, the absence of symptoms previous to admission, the absence, post mortem, of any indication of tuberculosis or organic disease to account for the conditions, and the absence of invasion (except an extremely small amount in the lungs) of the organs by the fibrous tissue growth. The case is recorded by the kind permission of Lieutenant-Colonel J. W. H. Brown, (T.D.), R.A.M.C. T.F., O.C. No.6 P. of W. Hospital, E.E.F.

\section{A NOTE ON}

\section{THE PRESENT EPIDEMIC OF INFLUENZA.}

By M. J. Rowlands, M.D. BRux., M.R.C.S., L.R.C.P., PATHOLOGIST, LEWISHAM MILITARY HOSPITAL; LATE PATHOLOGIST, ROYAX VICTORIA HOSPITAX, NETLEY.

DURING the present epidemic my commanding officer consulted me with a view to vaccine therapy. The results justify the treatment by vaccine, which up to the present is the only form that has given any satisfaction.

There have been, from a clinical point of view, three distinct types of cases.

First type.-This, which I will call the "Typhoidal type," is one of the most severe forms. The patient runs a temperature of $103^{\circ}$ to $104^{\circ} \mathrm{F}$., is wandering, the tongue is dry and brown, epistaxis is a marked symptom, also diarrhoea with some distension of the abdomen. The chest symptoms are a cough with little, if any, expectoration, and on physical examination fine crepitations are heard all over the chest. Respiration and pulse-rate are high. This type is usually fatal early in the disease. No post-mortems have been done, so that I am not able to discuss the morbid conditions. The examination of the sputa in these cases has shown that a Streptococous brevis is the chief offender, together with the Pfeiffer bacillus.

Second type. - I will call this the "Pleuro-pneumonia type." This does not differ from the ordinary case which one meets with in practice following exposures and colds. The type of pneumonia is usually lobar, and the pleurisy basal or diaphragmatic. Examination of sputum shows that the chief offending organisms with the Pfeiffer bacillus are Friedländer's bacillus and pneumococcus.

Third type.-This is the one in which the temperature may not be high, $101^{\circ}$ or $102^{\circ}$, but the great difficulty in getting sufficient air entry into the lung is very distressing to the patients. They are cyanosed and remain so, even though their temperature be nearly normal. They have an irritating cough, but little expectoration. The attacks of coughing very markedly increase the cyanosis ; the pulserate also rises and the pulse becomes intermittent. I have no doubt that this is due to enlargement of right side of heart. One patient is still markedly cyanosed, although his temperature has been normal for six days. The offending organism in this type, added to the Pfeiffer bacillus, is Miorooocous oatarrhalis.
Each of these types has been well marked in the cases under my care, and it seems fairly easy from the clinical aspect to diagnose the offending organism.

Space permits only a brief reference to the results of vaccine treatment. For example, during one week we treated 50 cases, all of which were acute, with only 2 deaths. Some of our stock bottles contained more streptococci than others, and some more pneumococci and $\boldsymbol{M}$. oatarrhalis. Which type was given depended upon the examination of the sputum. The vaccine was made up to a strength of 200 millions each per c.cm. of Pfeiffer bacillus, streptococcus, $\boldsymbol{M}$. catarrhalis, pneumobacillus, and pneumococcus. The initial dose given has been $0.4 \mathrm{c.cm}$. In no case has any evil effect been seen either on temperature or physical condition, and in almost every case very marked improvement. The same results have occurred in one's private practice. I am indebted to Colonel F. S. Toogood and his medical officers for their clinical assistance, also to $\mathrm{my}$ assistant, Miss Engall, who worked so hard at preparing and counting the vaccines.

Knightsbridge, S.W.

\section{INFLUENZA AND DIPHTHERIA.}

\section{By Evelyn A. Constable, M.B., B.S. Durh.,} IATE SURGICAL REGISTRAR, LONDON THMPERANOE HOSPITAL.

OTHER practitioners must have noticed that diphtheria is one of the occasional sequelæ of influenza. The usual pallor of diphtheria is in marked contrast to the flushed facies of the initial influenza in my experience during the September-November epidemic. (I was a victim myself to the June-July outbreak and hence was unable to make any observations then.) The following are some of the cases I can recall :-

CASE 1.-A boy, aged about 9 years, had typical influenza and very severe broncho-pneumonia. He was allowed up at the end of three weeks. "Two days later he complained of "sore throat." There was a sloughing patch on one tonsil and the glands in the neck were enlarged. The swab was positive and I sent the child to the fever hospital. When I saw him after his discharge, about eight weeks later, he was well.

CASE 2.-A girl, aged about 12 years, as well as her mother and adult brother and sister, had all been under my care for typical influenza. About two weeks after convalescence the patient developed marked pallor and a nasal discharge. Swabs positive for about three weeks. Recovery ensued.

CASE 3.-A girl, about 6 years of age, her father and brother all had influenza and bronchial catarrh. Two weeks after onset of influenza nasal discharge started in patient. Swab positive (brother's swab negative).

Cases 4 aNd 5.-A man, aged 38, had typical influenza. One week later membrane developed on right tonsil, with enlargement of submaxillary glands. He became very pale and ceased sweating. The swab was positive, and remained so for quite a month. One child became a carrier, and later his wife, who had had a very mild attack of influenza, developed a septic throat, which also gave a positive swab. Another child of this couple (aged 15 years) had fever and epistaxis. She was swabbed on two occasions with negative results ; this was interesting, as she had a large cleft-palate, thus giving one an unusually good view of the naso-pharynx. Her immunity was doubtless due to the fact that she had had diphtheria in infancy.

CASE 6.-A boy, aged a bout 8 years, had influenza, followed two weeks later by pharyngeal diphtheria. Swab positive. He developed a systolic murmur at cardiac apex; eventually did well.

CASE 7.-The patient in this case was a baby. A whole family had influenza and " doctored themselves." The baby Jeveloped membranous croup just after family were con valescent; sent to fever hospital at once. Made good recovery. Our medical officer of health, Dr. D. C. Kirkhope (who makes it a rule to swab all children of school-going age who have been in contact with any notified case), in this house discovered two other children with positive swabs (one a week and the other two or three weeks after the baby had been removed); acting on his advice they consulted me, as their family doctor, and in each case I found clinical diphtheria, and sent them to the fever hospital.

It is curious that all cases recovered from their double dose of toxin.

West Green, $\mathbf{N}$. 